\title{
Gestação de alto risco devido a doenças cardiovasculares pré-gestacionais
}

\author{
High-risk pregnancy due to pre-gestational cardiovascular diseases \\ Gestacione de alto riesgo debido a enfermedades cardiovasculares pregestacionales
}

Joice Carolina Machado dos Santos

ORCID: https://orcid.org/0000-0001-5919-6122

Centro Universitário de Santa Fé do Sul, Brasil

E-mail: joicecarolina@globomail.com

Larissa Regina Teixeira Meira

ORCID: https://orcid.org/0000-0002-5744-699X

Centro Universitário de Santa Fé do Sul, Brasil

E-mail: larissa_meira@outlook.com.br

Jussara Britto Batista Gonçalves

ORCID: https://orcid.org/0000-0003-3136-7932 Centro Universitário de Santa Fé do Sul, Brasil

E-mail: jsarabritto@gmail.com

Elena Carla Batista Mendes

ORCID: https://orcid.org/0000-0001-9471-8301 Centro Universitário de Santa Fé do Sul, Brasil

E-mail: ecbmarin@hotmail.com

Rogério Rodrigo Ramos

ORCID: https://orcid.org/0000-0003-1977-4172 Universidade Brasil, Brasil

Centro Universitário de Santa Fé do Sul, Brasil

E-mail: rogerio.enfer@gmail.com

Camila Maria Buso Weiller Viotto

ORCID: https://orcid.org/0000-0002-5967-7791

Centro Universitário de Santa Fé do Sul, Brasil

E-mail: camila.viotto3@etec.sp.gov.br

José Martins Pinto Neto

ORCID: https://orcid.org/0000-0002-6794-8379

Universidade Brasil, Brasi

Fundação Educacional de Fernandópolis, Brasil

E-mail: jmpintoneto@gmail.com

André Wilian Lozano

ORCID: https://orcid.org/0000-0002-5721-7054

Universidade Brasil, Brasil

Fundação Educacional de Fernandópolis, Brasil.

E-mail: lozanoenf@gmail.com

\begin{abstract}
Resumo
Compreender a realidade de uma gravidez de alto risco, bem como as sensações, medos e apreensões das mulheres nesse período. Estudo qualitativo, exploratório e descritivo com base nos depoimentos de sete mulheres com diagnóstico de doenças cardiovasculares pré-gestacionais classificadas como gestantes de alto risco. A técnica de análise temática do discurso utilizou três figuras metodológicas: a Ideia Central, as Expressões-Chave e o Discurso do Sujeito Coletivo. O estudo foi aprovado pelo Comitê de Ética em Pesquisa. A partir das falas, foram criados sete temas apresentados por quadros-síntese formados por Ideias Centrais que, por sua vez, emergiram os principais significados dos sentidos. São necessárias novas discussões sobre práticas de cuidado à gestante de alto risco que favoreçam o cuidado humanizado, integral, qualificado e a formação de vínculos efetivos para que o período seja vivido com segurança e autonomia.
\end{abstract}

Palavras-chave: Gravidez de alto risco; Cardiopatias; Saúde da mulher; Estratégia de saúde.

\begin{abstract}
Understand the reality of a high-risk pregnancy, as well as the sensations, fears and concerns by women during this period. The paper presents a qualitative, exploratory and descriptive study based on the testimonies of seven women diagnosed with pre-gestational cardiovascular diseases diagnosed as high-risk expectant. The technique of thematic discourse analysis used three methodological figures: The Main Idea, Key Expressions and the Collective Subject Discourse. The Research Ethics Committee approved the study. From the statements, seven topics were created, presented by summary tables consisting of Main Ideas, which, in turn, revealed the principal meanings of the senses. Seven women were interviewed, aged between 24 and 41. All women started in Primary Care and were later referred
\end{abstract}


to the high-risk pregnancy referral regarding prenatal care. New discussions are needed about care practices for highrisk pregnant women that favor humanized, critical, qualified care and the formation of effective bonds so that the period can be lived safely and autonomously.

Keywords: High-risk pregnancy; Heart diseases; Women's health; Health strategy.

\section{Resumen}

Compreender la realidade de vivir una gestación de alto riesgo, así como las sensasiones, miedos y aprensiones que experimentaran las mujeres en este transcurso. Estudio cualitativo, exploratorio y descriptivo basedo en los testimonios de siete mujeres diagnosticadas con enfermidades cardiovasculares pregestacionales classificadas como gestante de alto riesgo. La técnica del analisis temático del discurso utilizó tres figuras metodológicas: la Idea Central, las Expresiones Clave y el Discurso del Sujeto Colectivo. El estudio fue aprobado por el Comité de Ética e Investigación. A partir de los testimonios, se crearan siete temas presentados por tablas de sintesis compuestos por Ideas Centrales, que, a su vez, surgieron los principales significados de los sentidos. Se entrevistó siete mujeres, de entre 24 y 41 años. Relacionado al prenatal, todas las mujeres empezaran en la Atención Primaria y, posteriormente, fueran encamindas a la referencia de gestación de alto riesgo. Son necesarias nuevas discusiones acerca de las prácticas de precaución a las gestantes de alto riesgo que favorezcan la atención humanizada, integral, calificado y la formación de relaciones efectivas para que el período sea vivido con seguridad y autonomia.

Palabras clave: Gestación de alto riesgo; Cardiopatias; Salud de la mujer; Estratégia de salud.

\section{Introdução}

A gestação é um fenômeno fisiológico, sua evolução ocorre na maioria das vezes sem complicações. No entanto, existe uma pequena parcela das gestantes, cerca de $20 \%$ que, por ser portadora de alguma doença, sofreram ou desenvolveram algum problema, com uma evolução desfavorável tanto para o feto quanto para a mãe (Brasil, 2012; Rodrigues, et al., 2020). Costa et al. (2016) relatam as principais causas para uma gestação de alto risco, sendo infecção do trato urinário (21,3\%), obesidade (52,5\%), hipertensão arterial (52,4\%) e diabetes gestacional (1,6\%). Outros agravantes são as doenças cardíacas, consideradas a principal causa indireta de morte materna no ciclo gravídico puerperal. De acordo com as Diretrizes da Sociedade Brasileira de Cardiologia para Gravidez na Mulher Portadora de Cardiopatia no Brasil, a incidência de cardiopatias na gravidez é de 4,2\%, oito vezes maior quando comparada às estatísticas internacionais (Tedoldi, et al., 2009).

A mulher que tem uma gravidez de alto risco pode vivenciar maiores dificuldades nas adaptações emocionais exigidas pelo novo papel, agregando várias outras emoções àquelas que são sentidas por qualquer gestante. Isso porque, para a mãe, surge o medo de ocorrer uma má formação ou do nascimento pré-maturo no bebê ou o que está ocorrendo com o seu corpo, (Alves, et al., 2018; Antoniazzi, et al., 2019). Nesse ponto, a gravidez tende a deixar de ser vista apenas como maravilhosa e passa a ser ameaçadora para a mulher.

Cabe ao profissional de saúde ter conhecimento e sensibilidade para identificar e compreender o processo emocional que permeia o acompanhamento da gestação de alto risco e, assim, orientar as gestantes sobre as inevitáveis mudanças que irão se desenvolver neste período, para que sejam atendidas do mesmo jeito, o mais seguro possível, amenizando seus medos e ansiedades (Costa, 2010; Brasil, 2012; Oliveira, et al., 2015; Jardim, et al., 2019).

Diante desse contexto, o ponto de partida desta pesquisa foi o seguinte questionamento: quais os motivos que levaram as mulheres com doenças cardiovasculares a terem uma gestação de alto risco? Levando-se em consideração a hipótese de que mesmo quando educadas sobre o prognóstico, implicações e consequências para o quadro cardíaco, várias mulheres com doenças cardiovasculares decidem engravidar, ou continuar com a gravidez mesmo quando não planejada.

Por meio da contextualidade, o objetivo do estudo foi compreender a realidade de uma gravidez de alto risco, bem como as sensações, medos e apreensões das mulheres nesse período. 


\section{Metodologia}

A pesquisa trata-se de um estudo qualitativo, de caráter exploratório descritivo, no qual os depoimentos de mulheres com diagnóstico de doenças cardiovasculares pré-gestacionais foram classificados como gestantes de alto risco. O critério de seleção foi gestantes maiores de 18 anos, portadores de doenças cardiovasculares pré-gestacionais, que tivessem sido consultados durante o pré-natal na Unidade Básica de Saúde (UBS) de um município da região noroeste de São Paulo no período de $1^{\circ}$ de janeiro a 31 de março, 2019.

A pesquisa foi realizada pelo programa de iniciação cientifica (PIBIC) e aprovada pelo Comitê de Ética em Pesquisa do Centro Universitário de Santa Fé do Sul, sob protocolo n ${ }^{\circ}$ CAAE 29489520.1.0000.5428, sob o parecer de nº 4.103.095.

A amostra foi selecionada pela enfermeira chefe da UBS. As amostras foram compostas por 10 mulheres, porém, no momento da coleta de dados, duas não estavam na residência na data e horário agendados e uma mudou-se para outra cidade, portanto a amostra final foi composta por sete mulheres.

A coleta de dados ocorreu por meio da técnica de entrevista de análise temática, realizada por meio de um formulário semiestruturado contendo oito perguntas sobre dados socioculturais e seis perguntas por meio de gravação de áudio para posterior transcrição. Os temas em torno dos quais as entrevistas foram norteadas foram: experiências com a gravidez de risco; significados da maternidade, do filho e preocupações da gestante de alto risco em relação a si mesma e em relação ao bebê; conhecimento sobre os riscos da doença e relação com a equipe de saúde durante o pré-natal e puerpério.

As entrevistas foram realizadas no período de novembro de 2020 a janeiro de 2021. A escolha do local ficou a critério do participante, sendo que seis deles preferiram fazer na própria residência e uma escolheu a UBS.

Para o tratamento dos dados, empregou-se a técnica de análise de discurso temática, com utilização de três figuras metodológicas: a Ideia Central, as Expressões-Chave e o Discurso do Sujeito Coletivo. Segundo os criadores desta metodologia Simioni et al. (1996), a Ideia Central (IC) pode ser entendida como a síntese do conteúdo discursivo explicado pelos entrevistados, estando presente nas afirmações, negações e juízos de valor a respeito da realidade, bem como o contexto social em que os participantes da pesquisa estão envolvidos. Os trechos selecionados dos discursos que servem para ilustrar as Ideias Centrais são definidos como Expressões-Chave (CE), ou seja, são transcrições literais de parte dos depoimentos, contínuos ou não, que permitem resgatar sua essência.

Ainda segundo os autores supracitados, o Discurso do Sujeito Coletivo (DSC) é uma estratégia metodológica que visa tornar uma dada representação social mais clara, na qual busca agregar discursos, reconstruir, a partir de trechos individuais, tantos discursos homogêneos quanto julgar necessário expressar o pensamento daquele universo estudado sobre um fenômeno.

Para a organização dos discursos, foram realizados os seguintes procedimentos: (a) transcrição literal dos discursos e organização das mesmas na mesma ordem em que foram realizadas as entrevistas; (b) leitura do conjunto dos depoimentos coletados nas entrevistas; (c) leitura da resposta a cada pergunta particular, as partes mais importantes foram selecionadas grifando e colocando-se ao lado das mesmas o que foi chamado de IC provisória (d) transcrição das IC provisórias com suas respectivas EC referentes a cada entrevista de cada uma das participantes; (e) análise de todas as EC e IC, agrupando os semelhantes em conjuntos homogêneos, após mais algumas leituras, foram criadas as IC permanentes que deram origem aos grandes temas; (f) transformação e redução da lista de várias IC e de várias EC numa só, num discurso encadeado, como se houvesse um único indivíduo falando ser portador de um discurso-síntese de todos os indivíduos que compõem um dado sujeito coletivo. 


\section{Resultados}

\subsection{Caracterização das participantes}

Foram entrevistadas 07 mulheres, na faixa etária entre 24 a 41 anos de idade, $28,6 \%$ (2) relataram como escolaridade o ensino fundamental, $42,8 \%$ (3) chegaram ao ensino médio e $28,6 \%$ (2) possuem ensino superior completo. A renda mensal preponderante foi de 2 salários mínimos, 71,4\% (5) não exerciam qualquer atividade remunerada e se declararam como do lar. Sendo todas casadas, dentre essas uma em união estável.

Em relação ao pré-natal, todas deram início na Atenção Primária e, posteriormente, foram encaminhadas à referência de gestação de alto risco. O número de consultas durante a gestação variou entre 2 a 20 consultas. Destacou-se a prevalência do parto cesárea em $85,7 \%$ (6) das participantes, e a única participante que teve parto por via vaginal foi de gemelar, todos os partos foram realizados pelo SUS, dos quais somente duas das gestações foram planejadas.

\subsection{Análise do Discurso do Sujeito Coletivo}

Para a apresentação dos resultados, foram criados sete quadros-síntese formado por Ideias Centrais, que por sua vez emergiram os principais temas desta pesquisa.

Quadro - Síntese 1 - temas e ideias centrais.

\begin{tabular}{|c|}
\hline TEMA 1 - Sentimento diante da confirmação da gestação. \\
\hline Ideia Central 1 - Felicidade, queria muito um filho. \\
Ideia Central $2-$ Sentimentos ambíguos, preocupação e felicidade. \\
Ideia Central 3 - Sentimentos ambíguos, choque e felicidade. \\
Ideia Central $4-$ Desespero e preocupação, não planejava engravidar novamente. \\
Ideia Central 5 - Medo, por já ter vivenciado uma gestação de alto risco.
\end{tabular}

Fonte: Autores (2021).

Quadro - Síntese 2 - temas e ideias centrais.

TEMA 2 - Sentimentos vivenciados no decorrer da gestação de alto risco.

Ideia Central 1 - Incertezas, medo pela própria vida e do bebê.

Ideia Central 2 - Preocupação, se daria conta de cuidar dos filhos.

Ideia Central 3 - Realização, apesar dos riscos.

Ideia Central 4 - Fortalecimento espiritual

Fonte: Autores (2021).

Quadro - Síntese 3 - temas e ideias centrais.

TEMA 3 - Apoio familiar.

Ideia Central 1 - Suporte e apoio dos familiares durante a gestação e puerpério. 
Quadro - Síntese 4 - temas e ideias centrais.

\section{TEMA 4 - Desenvolvimento da gestação.}

Ideia Central 1 - Gestação sem intercorrência, mudanças de hábitos e estilo de vida. Ideia Central 2 - Intercorrências na gestação, no parto e pós-parto.

Fonte: Autores (2021).

Quadro - Síntese 5 - temas e ideias centrais.

TEMA 5 - Conhecimento/orientação prévio sobre riscos decorrentes de uma gestação associada à doença cardiovascular.

Ideia Central 1 - Possuia conhecimento, havia recebido orientação e decidiu engravidar.

Ideia Central 2 - Possuia conhecimento, havia recebido orientação e não desejava engravidar.

Ideia Central 3 - Não tinha conhecimento e não recebeu orientação sobre os riscos da gestação.

Fonte: Autores (2021).

Quadro - Síntese 6 - temas e ideias centrais.

TEMA 6 - Relacionamento com a equipe de saúde durante a gestação e parto.

Ideia Central 1 - Bom relacionamento com a equipe, satisfação com o atendimento recebido.

Ideia Central 2 - Bom relacionamento com a equipe, insatisfação com o atendimento médico.

Ideia Central 3 - Bom relacionamento com a equipe, insatisfação com o atendimento/apoio emocional.

Fonte: Autores (2021).

Quadro - Síntese 7 - temas e ideias centrais.

TEMA 7 - Significado da maternidade e do filho.

Ideia Central 1 - Realização, um amor imenso e sem explicação, supera o medo.

Ideia Central 2 - Este filho será o último.

Ideia Central 3 Filho tem significado especial por causa das dificuldades que a mãe vivenciou durante a gestação. Ideia Central 4 - Não era planejado, mas hoje é tudo na minha vida.

Ideia Central 5 - Nova experiência de aprendizado.

Fonte: Autores (2021).

Mediante as Ideias Centrais identificadas nos discursos individuais das participantes da pesquisa foi possível formular os DSC descritos a seguir. 


\section{TEMA 1 - Sentimento diante da confirmação da gestação.}

Ideia Central 1 - Felicidade, queria muito um filho. (P1)

"Ah me senti feliz, porque a gente queria muito eu e meu marido. Antes dele eu perdi dois bebês (...) ai quando confirmou mesmo todo mundo ficou feliz, até porque a gente queria muito mesmo, inclusive pra ele (filho mais velho) não crescer sozinho".

Ideia Central 2 - Sentimentos ambíguos, preocupação e felicidade. (P2)

"Me senti um pouco preocupada, que na minha primeira gestação tinha passado por problemas por causa da hipertensão, mas estava feliz né”.

Ideia Central 3 - Sentimentos ambíguos, choque e felicidade. (P4, P5)

"Primeiro eu levei um susto, porque eu não estava esperando né e depois eu fiquei feliz por saber que era uma gestação e não uma coisa pior (...) Foi um susto muito grande, mas depois fiquei alegre, fiquei feliz. Eu fiquei feliz e ao mesmo tempo chorei muito por conta que nesse tempo que eu engravidei eu estava passando por dificuldades".

Ideia Central 4 - Desespero e preocupação, não planejava engravidar novamente. (P3, P6)

"Na hora minha pressão subiu e eu desmaiei, demorei pra voltar. Pra mim foi um choque, a minha filha mais velha estava com 25, a M.E. tinha 15 anos, então pra mim seria o fim das gestações eu não teria mais filhos, seriam só as duas né, não ia ter mais. Muito mal, vixi muito apavorada. Assim fiquei em choque né, não foi planejada não queria mais né, porque o meu mais velho tem 9 anos, fiquei muito mal, achei que ia entrar em depressão pós-parto, mas depois ficou tudo bem, mas no começo eu fiquei bem abalada".

Ideia Central 5 - Medo, por já ter vivenciado uma gestação de alto risco. (P7)

"Ai, foi uma mistura de sentimentos porque a primeira como foi complicada né, eu tive a pré-eclampsia, depois tive a embolia pulmonar, então eu fiquei com medo, mas feliz ao mesmo tempo né porque é uma vida e uma vida é um milagre né (...) Para falar a verdade, mais medo porque eu já sabia que não ia ser fácil”.

\section{TEMA 2 - Sentimentos vivenciados no decorrer da gestação de alto risco.}

Ideia Central 1 - Incertezas, medo pela própria vida e do bebê. (P1, P4, P6, P7)

"Olha não foi fácil, porque todo momento você fica pensando 'será que vai dar certo', 'será que no parto vai ocorrer tudo bem', 'será que o bebê vai nascer com algum problema', enquanto não nasce a cabeça não para. Foi tenso né, a gente vive com medo. Foi assim complicado porque, mas ... passou. Ai eu me senti muito mal, não assim pela criança né, a gente no começo fica meio ... mas a gente sente mal né, fica com medo né de acontecer alguma coisa comigo mesmo, acontecer e eu, vamos supor que o médico já falou, 'óh corre o risco da mãe ir e a gente salvar a criança e acontece dos dois também', então eu ficava pensando, já pensou se eu for primeiro, se eu for embora e quem vai cuidar dos meus filhos depois né? Eu fiquei mais preocupada, fiquei mais atenta aos exames, porque como aconteceu da primeira eu não queria que acontecesse na segunda". 
Ideia Central 2 - Preocupação, se daria conta de cuidar dos filhos. (P3)

"Perdi várias noites de sono pensando 'como que eu vou fazer agora pra cuidar de duas crianças se tem mãe que não consegue cuidar de uma' e principalmente na amamentação 'meu Deus, como que eu vou poder amamentar essas duas crianças?"

Ideia Central 3 - Realização, apesar dos riscos. (P5)

"Foi bom né, foi assim de todos eles, eu acho que foi o melhor por conta que nos outros eu era muito nova, desse ai eu já tinha mais, sei lá, amo a todos, só que assim esse pequeno veio pra me derrochar, mas foi gostoso, foi foi muito bom”.

Ideia Central 4 - Fortalecimento espiritual (P3, P5, P6, P7).

“... então foi tudo assim entregue na mão de Deus ... eu só pedia para que Jeová me desse força, para que meus filhos pudessem nascer perfeitos né, com saúde os dois. Como diz minha mãe 'Deus dá o fardo que a gente consegue carregar'. Ai entreguei nas mãos de Deus e graças a Deus hoje ... ele nasceu perfeito, perfeito, olha foi tanta coisa, tanta coisa que só Deus ... eu sei que Deus foi abrandando meu coração e ... foi acontecendo né, mas graças a Deus deu tudo certo. Graças a Deus eu fui até o final da gestação, se Deus mandou mais um é pra eu criar né e que ia correr tudo bem. Tanto que foi por Deus mesmo que eu não tive uma trombose e um parto prematuro na segunda né”.

\section{TEMA 3 - Apoio familiar.}

Ideia Central 1 - Suporte e apoio dos familiares durante a gestação e puerpério. (P1, P7)

"Tive apoio de toda minha família, eu moro no fundo da casa da minha sogra, ela me ajudava, meu marido chegava do serviço cansado e limpava casa e limpava tudo pra mim, quando não minha mãe vinha pra me ajudar, depois que ganhei ele ficou na casa da minha mãe até me recuperar. O principal apoio que eu tive foi do meu marido, quando eu mais precisei ele estava presente, ficava em casa cuidando de mim e das meninas".

\section{TEMA 4 - Desenvolvimento da gestação.}

Ideia Central 1 - Gestação sem intercorrência, mudanças de hábitos e estilo de vida (P1, P4, P7).

“A médica viu que minha pressão estava subindo muito, na época eu trabalhava na rua, ela falou que eu não podia trabalhar, por causa do sol, essas coisas. Eu comecei a tomar remédios em casa, ai eu fiquei em casa, eu fiquei de repouso mas não precisou de internação. Então eu fiz todos os exames, sempre atenta, a alimentação eu mudei completamente”.

Ideia Central 2 - Intercorrências na gestação, no parto e pós-parto (P3, P6, P7).

"Além de pressão alta eu tenho problema de coração, um buraquinho no coração, me falaram que toda criança tem e o meu com o passar do tempo ele abriu, e ai depois disso (parto) deu uma flebite na minha perna, um começo de trombose, eu fiquei 34 dias internada. Porque eu retenho muito líquido, incho muito, e a Dr. falou vou ficar com você aqui, olhando você aqui, só que você vai pra lá (referência de alto risco), porque lá tem todo um recurso, até ela mesma falou pra mim não ficar aqui ... Meu menino nasceu sem respirar no dia ... eu só não perdi ele porque foi um milagre, porque lá tem recurso né ... Eu pedi pro vascular depois que eu ganhasse neném que eu tomasse Clexane porque ele não queria me passar Clexane, tomei 20 injeções por isso que a trombose acho que veio depois mais a frente porque quando eu parei de tomar o anticoagulante ai que começou a coagular o sangue e formar os trombos na perna”. 


\section{TEMA 5 - Conhecimento/orientação prévio sobre riscos decorrentes de uma gestação associada à doença cardiovascular.}

Ideia Central 1 - Possuia conhecimento, havia recebido orientação e decidiu engravidar. (P1, P2)

“Eu conversei com minha médica perguntei se eu poderia engravidar novamente, ela falou que poderia ter complicações, principalmente sobre meu peso que estou um pouco acima e a pressão no final, mas eu queria muito então eu insisti e decidimos tentar. A gente sabe que poderia ter uma pré eclampsia, uma eclampsia, nesse caso correndo risco de vida né, sou da área né, sou enfermeira eu já sabia que seria complicado”

Ideia Central 2 - Possuia conhecimento, havia recebido orientação e não desejava engravidar. (P4, P5, P7)

“Já tinha sido orientada, recebi pela minha primeira gravidez né, ai a gente já pegou o jeito. Já, já, perguntavam pra mim se eu queria engravidar de novo, só que ai como ele veio sem eu esperar. Na primeira gestação como eu tive a préeclampsia e depois eu tive trombose com embolia pulmonar, os médicos já recomendaram que eu não engravidasse, então assim eu não usava nenhum contraceptivo, mas evitava de outras maneiras, tanto que eu engravidei depois de treze anos".

Ideia Central 3 - Não tinha conhecimento e não recebeu orientação sobre os riscos da gestação. (P3, P6)

"De nenhum médico eu tive orientação em relação à risco de engravidar, até porque eu não sabia que eu tinha esse problema na minha válvula mitral. Não fui muito orientada sobre os riscos não, porque aqui é, os médicos são bons aqui, só que aqui falta muita, é, como que fala, como que eu digo, falta muita é, sei lá, pros médicos explicar melhor”.

\section{TEMA 6 - Relacionamento com a equipe de saúde durante a gestação e parto.}

Ideia Central 1 - Bom relacionamento com a equipe, satisfação com o atendimento recebido. (P1, P2, P5, P6, )

"Sempre que precisava eu ia lá (local onde realizou o pré-natal) e elas sempre me ajudavam, elas me auxiliavam, encaixava e eu já ficava lá, todas as vezes o atendimento foi muito bom, tanto em R.P (local de referência de alto risco) quanto aqui, sempre me ajudando quando eu precisei. Sempre fui bem atendida, acolhida, o pessoal e a doutora sempre me trataram bem. No pré-natal eu recebia as orientações certinho, sobre as medicações, tanto com Dr. tanto com as meninas que ficavam lá, me passavam direitinho. Olha, a Dr. aqui foi muito atenciosa, nunca tinha feito pré-natal com ela, ela foi muito atenciosa, muito boazinha, as meninas lá também, as enfermeiras lá da clínica, um atendimento bem, nunca me deixou faltar nada”.

Ideia Central 2 - Bom relacionamento com a equipe, insatisfação com o atendimento médico. (P3, P7)

“Na parte do pré-natal não me faltou nada, as meninas lá (local onde realizou o pré-natal) são muito legal, a enfermeira tudo sempre me orientando. Eu acho que faltou por parte dos médicos. Por ser um caso de alto risco, porque eu procurei o médico que me falaram que era de alto risco aqui e ele deveria ter dado mais atenção pro meu caso, poderia ter evitado muita coisa. "quando me mandaram para Santa Casa a pediatra perguntou porque eu não fui ganhar na referência já que lá tem UTI neonatal e aqui não, e eu tenho vários tipos de problemas, mas a gente não tem carro pra ir pra lá, a pediatra ainda falou que dava tempo de pedir pra alguém um vizinho ou amigo pra levar, mas na hora que eu entrei na sala de parto a obstetra disse pra mim assim "se você pegar a estrada junto com seus filhos vai morrer você e eles, não vai ser uma coisa segura, vamos entregar nas mãos de Deus, já fiz partos de crianças com 0,800 kg e sobreviveram então os seus vão sobreviver também”, então ela arriscou né, no meu parto a pediatra abriu a porta da sala de parto e tinha várias pessoas assistindo o meu parto, até porque hoje em dia quem tem gêmeos faz cesárea né, é difícil ter parto normal, e eu já tinha 41 anos com todos esses problemas, muito arriscado, ai ela abria a porta e falava pra obstetra que se acontecesse alguma coisa ela não iria se 
responsabilizar, que sabia que minha situação era de risco, que ali não tinha neonatal e não sei o que, e nisso ela ficou com a porta aberta e a obstetra me acalmava e minha filha mais velha que assistiu o parto me acalmava, e eu só chorava, eu não tinha força pra fazer a menina nascer, o menino já tinha nascido, ai menina eu comecei a chorar, minha pressão começou a subir, aquilo tudo eu tive a menina com a minha força mesmo ... depois ela me colocou num quarto e eu não podia pedir ajuda pra ninguém, no quarto as pessoas tinham feito cesárea, eu acho que ela não deveria ter feito isso, deveria ter me colocado com as pessoas que fizeram normal, ela não deixou ninguém de acompanhante comigo, eu fiquei sozinha, não tinha ninguém, nem meu marido, ai na hora de amamentar coloca um de cada lado quando eles choravam, sentava na cadeira e amamentava, e as meninas que tinham feito cesárea não podiam fazer nada por mim, ficavam com dó, mas eu tinha que amamentar eles".

Ideia Central 3 - Bom relacionamento com a equipe, insatisfação com o atendimento/apoio emocional. (P4)

“A relação com a equipe foi bom, foi muito bom. O pessoal da C. M. me atendeu bem, a doutora me atendeu bem. Só faltou o apoio psicológico, porque assim né é tudo novo né, então a gente fica meio assim né, então eu acho que falta é isso é um apoio mais psicológico tanto da enfermagem quanto das próprias psicólogas mesmo, falta isso pra conversar, pra orientar melhor, não que não oriente, orienta muito bem tudo, mas falta um pouquinho mais. Não sei se a demanda é muito grande pra um lugar só, sobrecarrega os funcionários entendeu, mas falta esse, esse acolhimento mesmo”.

\section{TEMA 7 - Significado da maternidade e do filho.}

Ideia Central 1 - Realização, um amor imenso e sem explicação, supera o medo. (P1, P2)

“Eu não tenho palavras pra explicar, mas fala pra vocês é um amor imenso, não tem explicação. Tinha hora que o medo batia forte, mas o amor supera o medo. Uma nova vida né, um recomeço”.

Ideia Central 2 - Este filho será o último. (P2, P6)

"Mas encerrando por ai também, duas geestações complicadinhas já está bom (risos). Foi uma experiência pra mim grande assim que eu não quero passar de novo não. Foi boa, mas não quero mais não”.

Ideia Central 3 - Filho tem significado especial por causa das dificuldades que a mãe vivenciou durante a gestação. (P3, P4)

"Hoje eu olho pros meus filhos eu admiro por tudo que eu passei, o tempo passou e hoje eles são o meu alicerce, porque eu tenho uma depressão e tomo remédios a muitos anos, e minha depressão era muito pior quando eu não tinha eles, depois que eu tive eles ela diminuiu, me sinto melhor, antes eu só chorava, queria ficar sozinha, tinha crises sabe, não queria falar com ninguém. Eles foram meu alicerce e me levantaram. Eu tive o meu bem mais precioso que é o meu filho né, acho que é por isso que a gente fica tão tensa, tão com medo, porque é uma coisa né que a gente quer muito".

Ideia Central 4 - Não era planejado, mas hoje é tudo na minha vida. (P5)

"Significou muito assim, é ... Sei lá, mas assim foi uma coisa boa, não foi planejada por mim, mas foi uma coisa muito boa que aconteceu na vida da gente e significou tudo né, porque um filho é tudo né, é uma benção de Deus e agora está sendo uma alegria menina, mas foi muito bom”.

Ideia Central 5 - Nova experiência de aprendizado. (P7)

"Pra mim, foi um aprendizado e foi uma mistura de muitos sentimentos e assim o que achei, o que mais me tocou nessa gestação foi porque eu consegui viver o que eu não tive na primeira, porque a minha primeira gestação foi interrompida, então eu consegui sentir os movimentos do neném na minha barriga”. 


\section{Discussão}

Ao examinar as falas das participantes, destacaram-se 7 temas dos quais emergiram diferentes Ideias-Centrais que representam os diversos significados socialmente construídos e significados pessoais atribuídos à maternidade, que se refletem nos comportamentos relacionados ao desejo e a escolha de ser mãe mesmo na presença de doença cardiovascular.

No Tema 1, nas falas associadas à não programação da gravidez, houve predomínio de sentimentos ambíguos em relação à confirmação da mesma, refletindo um misto de felicidade, preocupação, choque e medo, em alguns casos levando até ao desespero por já ter vivenciado uma gravidez de alto risco. Entretanto, quando existe o desejo de ter um filho e essa decisão é tomada de forma consciente, seja pelo aprofundamento da relação homem-mulher, quer seja pelo desejo de preencher um vazio interno ou por assumir um papel tão valorizado socialmente de ser mãe, o sentimento referido é positivo, o de felicidade.

Em todo caso, a mulher que engravida revela satisfação e felicidade, pela realização do desejo de ter um filho, mesmo com medo e em circunstâncias que envolvam perigo para a própria saúde (Oliveira \& Mandu, 2015; Riegert, et al., 2018; Vieira, et al., 2019), fato este presente no Tema 2, que apesar dos sentimentos negativos que permearam o processo gestacional, todas as participantes seguiram adiante com a gestação tendo como aliadas a fé e a espiritualidade, lutando dia a dia pela própria vida e pela vida do bebê, superando todas as dificuldades e levando à realização pessoal.

A gravidez e o puerpério são períodos cruciais, tanto biológicos, quanto psicológicos, devido as alterações fisiológicas que preparam a gestante para o parto, nascimento e cuidados posteriores. Dessa forma, nesta fase torna-se imprescindível a revisão dos papeis sociais e familiares (Fave, et al., 2013; Errico, et al., 2018). Nos discursos presentes no Tema 3, destacaramse a presença do apoio familiar, tanto no desenvolvimento da gestação quanto no puerpério, evidenciando-se a influência que o apoio familiar pode exercer como fator de proteção percebido e vivenciado pelas participantes.

Além do papel familiar, outro fator importante que teve influência direta no bom desenvolvimento do ciclo gravídicopuerperal foram as adaptações e mudanças exigidas por este período. Verifica-se no Tema 4 que as mulheres que tiveram gestações planejadas, se prepararam e se adaptaram para a nova realidade, por meio da adoção de novos hábitos e mudanças no estilo de vida, tiveram uma gestação e puerpério mais tranquila, sem intercorrências significativas. Em contrapartida, as que não estavam preparadas, encontraram maiores dificuldades de adaptação com a nova realidade e, como consequência, passaram por intercorrências antes, durante e após o parto.

A partir das falas das participantes referentes ao Tema 5, observa-se que a responsabilização da ocorrência da gestação de alto risco está relacionada tanto ao comportamento do casal em relação à contracepção quanto ao papel da equipe de saúde responsável pelas orientações sobre planejamento familiar e assistência, pois verifica-se nos discursos que quando a mulher tinha conhecimento e foi orientada quanto aos riscos de uma gestação na presença de uma doença cardiovascular ocorreram duas situações: para algumas a gravidez foi acidental, entretanto previsível pelo uso negligenciado do método contraceptivo, e para outras foi intencional.

As mulheres que vivenciam uma gestação de alto risco necessitam, principalmente no momento da comunicação da confirmação da gravidez, receber informações e orientações claras por parte dos profissionais que acompanham o pré-natal, visto que isto é um direito de todas previsto pela Política Nacional de Atenção Integral à Saúde da Mulher (Brasil, 2011; Amorim, et al., 2016) que tem como objetivo primordial garantir a melhoria do acesso, cobertura e qualidade da atenção ao pré-natal, parto e puerpério à gestante e ao recém-nascido, na perspectiva dos direitos de cidadania, além de uma assistência qualificada que promova segurança, apoio sobre o processo gestacional e desenvolvimento fetal, pautada em preceitos holísticos.

As atitudes de afetividade e sensibilidade expressas pela equipe multiprofissional a essas gestantes faz com que surja um vínculo mais forte entre elas, facilitando assim o desenvolvimento de ações preventivas e de promoção a saúde (Moura \& 
Gomes, 2014; Tostes, 2016; Costa, et al., 2019). Porém, muitas vezes, os profissionais se detêm aos aspectos fisiológicos da gestação e ao diagnóstico clínico e terapêutico e não percebem a real necessidade que essas gestantes possuem de serem acolhidas por um atendimento integral e qualificado que garanta a expressão de sentimentos (Costa, et al., 2019), fator este que acarreta numa falha na atuação da equipe multidisciplinar, como presente nos discursos do Tema 6 , que destacou a insatisfação em relação ao atendimento médico recebido, incluindo obstetra e pediatra, em algumas falas em especial (Tema 6, IC 2) em que nota-se uma completa falta de humanização para com a paciente.

Por fim, as experiências vivenciadas durante a gestação de alto risco por ser associada a doenças cardiovasculares, por envolverem aspectos/adaptações tanto biológicos quanto psicológicos, influenciam nos diversos significados atribuídos para a maternidade e para o filho, fato presente nos discursos do Tema 7, nos quais se destacam os sentimentos maternos positivos como: realização, superação do medo, recomeço, amor sem fim, vitória e aprendizado, o que reflete no fortalecimento do vínculo mãe-filho e no desejo de não ter mais filhos.

\section{Conclusão}

O estudo permitiu identificar multiplicidade de sentimentos, significados e percepções sobre a maternidade de mulheres que vivenciaram uma gravidez de alto risco, desde o recebimento da confirmação da gravidez até ao significado atribuído ao filho. Quando não havia programação da gestação, foram manifestadas reações iniciais negativas, contudo, a maioria das mulheres encontraram formas positivas de enfrentar e lidar com as doenças cardiovasculares e as dificuldades impostas por uma gravidez de alto risco.

A análise dos discursos revelou a importância do apoio familiar e a necessidade de uma assistência humanizada, integrada e qualificada, haja vista a necessidade das novas exigências biológicas e emocionais do período. Além disso, a atuação da equipe multiprofissional é importante na assistência desde a saúde sexual e reprodutiva até o pré-natal de alto risco, que incluem orientações sobre planejamento familiar, assistência integral e formação de vínculo efetivo, evitando possíveis gestações não planejadas, mortes maternas e perinatais. Sugere-se mais estudos sobre a temática apresentada no sentido de fortalecer as ações e medidas que devem ser realizadas para uma assistência segura e integral permitindo a autonomia das mulheres frente às suas decisões.

\section{Conflito de Interesses}

Os autores declaram não haver conflito de interesses.

\section{Referências}

Alves, G. M. A. N., Rodrigues, O. M. P., \& Cardoso, H. F. (2018). Indicadores emocionais de mães de bebês com risco para o desenvolvimento. Pensando Famílias, 22(2), 70-87. http://pepsic.bvsalud.org/scielo.php?script=sci_arttext\&pid=S1679-494X2018000200006\&lng=pt\&nrm=iso

Amorim, T. V., Souza, Í. E. O., Salimena, A. M. O. Melo, M. C. S. C., Paiva, A. C. P. C., \& Moura, M. A. V. (2016). Cotidiano da gravidez de risco por cardiopatia: estudo fenomenológico das relações assistenciais. Escola Anna Nery, 20(4), e20160091. http://dx.doi.org/10.5935/1414-8145.20160091

Antoniazzi, M. P., Siqueira, A. C., \& Farias, C. P. (2019). Aspectos psicológicos de uma gestação de alto risco em primigestas antes e depois do parto. Pensando famílias, 23(2), 191-207. http://pepsic.bvsalud.org/scielo.php?script=sci_arttext\&pid=S1679-494X2019000200015

Brasil. (2012). Ministério da Saúde. Gestação de alto risco: manual técnico / Ministério da Saúde, Secretaria de Atenção à Saúde, Departamento de Ações Programáticas Estratégicas. 5 ed. Brasília: Ministério da Saúde. http://bvsms.saude.gov.br/bvs/publicacoes/manual_tecnico_gestacao_alto_risco.pdf

Brasil. (2011). Ministério da saúde. Política Nacional de Atenção Integral à Saúde da Mulher: Princípios e Diretrizes / Ministério da Saúde, Secretaria de Atenção à Saúde, Departamento de Ações Programáticas Estratégicas. 1 ed., $2 . \quad$ reimpr. Brasília: Ministério da Saúde. https://bvsms.saude.gov.br/bvs/publicacoes/politica_nacional_mulher_principios_diretrizes.pdf

Costa, E. S., Pinon, G. M. B., Costa, T. S., Santos, R. C. A., Nóbrega, A. R., \& Sousa, L. B. (2010). Alterações fisiológicas na percepção de mulheres durante a gestação. Rev Rene, 11(2), 86-93. http://www.periodicos.ufc.br/rene/article/view/4531 
Costa, L. D., Hoesel, T. C., Teixeira, G. T., Trevisan, M. G., Backes, M. T. S., \& Santos, E. K. A. (2019). Percepções de gestantes internadas em um serviço de referência de alto risco. Revista Mineira de Enfermagem, 23, e-1199. https://pesquisa.bvsalud.org/portal/resource/pt/biblio-1051451

Costa, L. D., Cura, C. C., Perondi, A. R., França, V. F., \& Bortoloti, D. S. (2016). Perfil epidemiológico de gestantes de alto risco. Cogitare Enfermagem, 1(2), 01-08. https://revistas.ufpr.br/cogitare/article/view/44192

Errico, L. S. P., Bicalho, P. G., Oliveira, T. C. F. L., \& Martins, E. F. (2018). O trabalho do enfermeiro no pré-natal de alto risco sob a ótica das necessidades humanas básicas. Revista Brasileira de Enfermagem, 71(suppl. 3), 1257-1264. http://dx.doi.org/10.1590/0034-7167-2017-0328.

Fave, A. D., Pozzo, A., Bassi, M., \& Cetin, I. (2013). A longitudinal study on motherhood and well-being: Developmental and clinical implications. Terapia psicológica, 31(1), 21-33. http://dx.doi.org/10.4067/S0718-48082013000100003

Jardim, M. J. A., Silva, A. A., \& Fonseca, L. M. B. (2019). The nurse's contributions in prenatal care towards achieving the pregnant women empowerment. Journal of Research: Fundamental Care Online, 11(2), 432-440. http://dx.doi.org/10.9789/2175-5361.rpcfo.v11.6370

Moura, L. N. B., \& Gomes, K. R. O. (2014). Planejamento familiar: uso dos serviços de saúde por jovens com experiência de gravidez. Ciência \& Saúde Coletiva, 19(3), 853-863. https://doi.org/10.1590/1413-81232014193.10902013

Oliveira, J. C. S., Fermino, B. P. D., Conceição, E. P. M., \& Navarro, J.P. (2015). Assistência pré-natal realizada por enfermeiros: O olhar da puérpera. Revista de Enfermagem do Centro Oeste Mineiro, 5(2), 1613-1628. http://www.seer.ufsj.edu.br/index.php/recom/article/view/857

Oliveira, D. C., \& Mandu, E. N. T. (2015). Mulheres com gravidez de maior risco: vivências e percepções de necessidades e cuidado. Escola Anna Nery, 19(1), 93-101. https://www.scielo.br/pdf/ean/v19n1/1414-8145-ean-19-01-0093.pdf

Riegert, I. T. et al. (2018). Avaliação da satisfação de puérperas em relação ao parto. Revista de Enfermagem UFPE On Line, 12(11), 2986-93. https://doi.org/10.5205/1981-8963-v12i11a236863p2986-2993-2018

Rodrigues, A. R. M., Rodrigues, D. P., Silveira, M. A. M., Paiva, A. M. G., Fialho, A. V. M., \& Queiroz, A. B. A. (2020). Hospitalização na gravidez de alto risco: representações sociais das gestantes. Revista de Enfermagem Referência, 5(3), e20040. https://revistas.rcaap.pt/index.php/referencia/article/view/21479

Simioni, A. M. C. Lefèvre, F., \& Bicudo, P. I. M. T. (1996). Metodologia qualitativa nas pesquisas em saúde coletiva: considerações teóricas e instrumentais. Especialização (Monografia em Saúde Pública) - Faculdade de Saúde Pública, Universidade de São Paulo, São Paulo, p. 21. https://pesquisa.bvsalud.org/portal/resource/pt/lil-184760

Tedoldi, C. L. et al. (2009). Sociedade Brasileira de Cardiologia.Diretriz da Sociedade Brasileira de Cardiologia para Gravidez na Mulher Portadora de Cardiopatia. Arquivos Brasileiros de Cardiologia, 93(6 supl.1), e110-e178. http://publicacoes.cardiol.br/consenso/2009/diretriz_card_grav_9306supl1.pdf

Tostes, N. A., \& Seidl, E. M. F. (2016). Expectativas de gestantes sobre o parto e suas percepções acerca da preparação para o parto. Temas em Psicologia, 24(2), 681-693. http://dx.doi.org/10.9788/TP2016.2-15

Vieira, V. C. L., Barreto, M. S., Marquete, V. F. Souza, R. R., Fischer, M. M. J. B., \& Marcon, S. S. (2019). Vulnerabilidade da gravidez de alto risco na percepção de gestantes e familiares. Rev Rene, 20(19), 40207. https://pesquisa.bvsalud.org/portal/resource/pt/biblio-997317 